\title{
Crack and Leakage Detection on Underground Pipelines Using Acoustic Technique
}

\author{
Aidy Ali*, Ahmad Firdaus AT and Amirul Faiz K \\ University Pertahanan Nasional Malaysia (UPNM), Malaysia
}

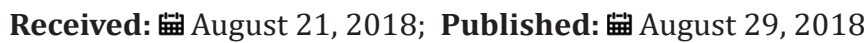

*Corresponding author: Aidy Ali, Department of Mechanical Engineering, University Pertahanan Nasional Malaysia (UPNM), Malaysia

\begin{abstract}
In this study, a method of water leakage detection system was investigated using acoustic emission device, AQUA M 300D. It is used to pinpoint leakage sources for underground pipelines system. The leakage is detected by analyzing the feedback frequency, where leakage area produces higher frequency due to the vibration resulting from a high-pressure liquid that flows through the crevice. The method is successful to detect underground pipelines system leakage with $90 \%$ accuracy.
\end{abstract}

\section{Introduction}

Every year, the government spends high budget on improving water pipeline system by doing maintenance, replacing older water pipeline, and locating leakage area. There are large percentage of water loss due transportation from sources or treatment plants to users. Water loss can be attributed by several causes including leakage, metering error and misuse of public usage [1]. But, water loss due to leakage contributes a larger percentage [2]. There are several methods that can be used to detect water leakage. However, in this study, acoustic emission technique has been chosen as it is the best non-destructive test for underground water pipelines $[3,4]$. The tests of efficiency and compatibility of the technique in detecting underground water pipelines is explored. This paper will also discuss the failure analysis that commonly occurs, and the factors lead to it. The test is conducted at Universiti Pertahanan Nasional Malaysia.

\section{Instrumentation}

\section{Acoustic Detector AQUA M300 D}

Figure 1 shows the AQUA M300 D, a multi-purpose detector designed to allow the user to carry out electro acoustic leak detection on pipe systems carrying water, acoustic leak detection on pipes, and to perform non-destructive pinpoint leak detection on pipes which have previously been flooded with trace gas using the indicative measurement of different hydrogen concentrations.

\section{Experimental Procedure}

Acoustic Detector AQUA M300 D is used to record frequency readings at the possible leakage locations. Four locations have been selected, which are pipe located under the road, parking lot, chancellor building, and Block C4.

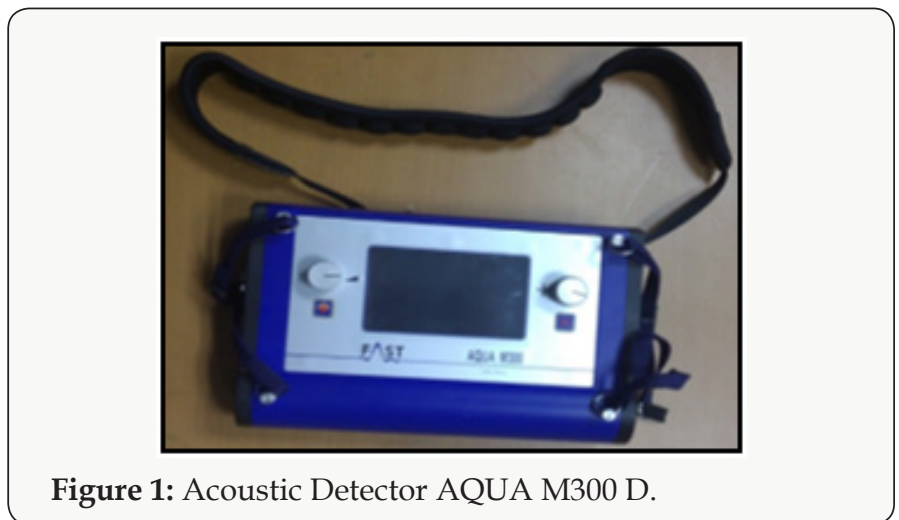

Results and Discussions

Case Study 1: Leakage from Pipe Located Under the Road

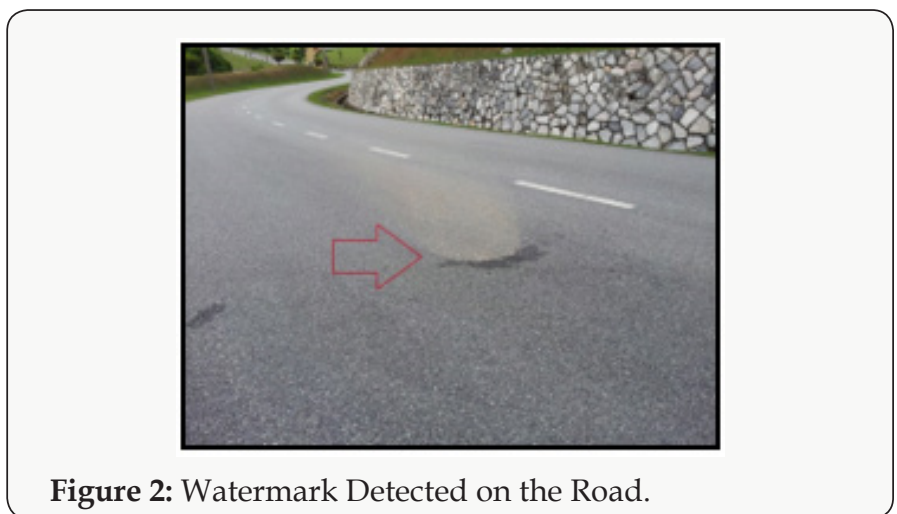




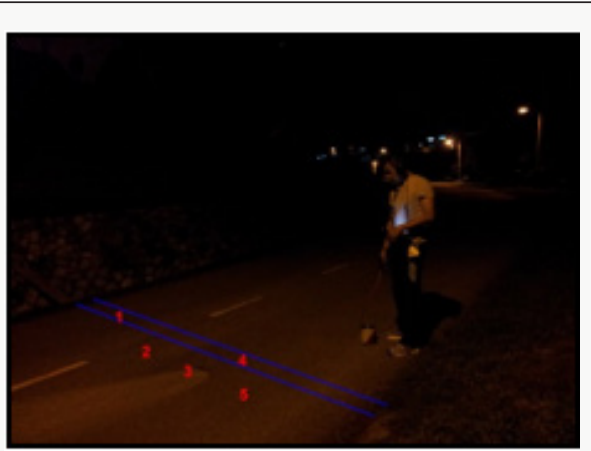

Figure 3: Locating Leakage Source of Underground Water Pipeline.
Figure 2 below shows watermark appear on the road surface due to leakage or crack in underground water pipeline. Five readings have been taken to determine the sources of the leakage as shown in Figure 3 The readings are displayed in the (Table 1) From the table, it shows that frequency reading at point 4 is the highest compared to other points. The high frequency is emitted due to occurrence of underground water pipeline leakage or crack. It is resulting from the vibration that is produced by a high-pressure water flow through crevice in the water pipeline. The smart bar indicator will increase when the frequency increases. That indicates that the range of potential leakage pinpoint is narrowed down. The area that does not have water pipe shows low reading because there is no vibration occurred due to water flow.

Table 1: Loudness Graph from Watermark on the Road.

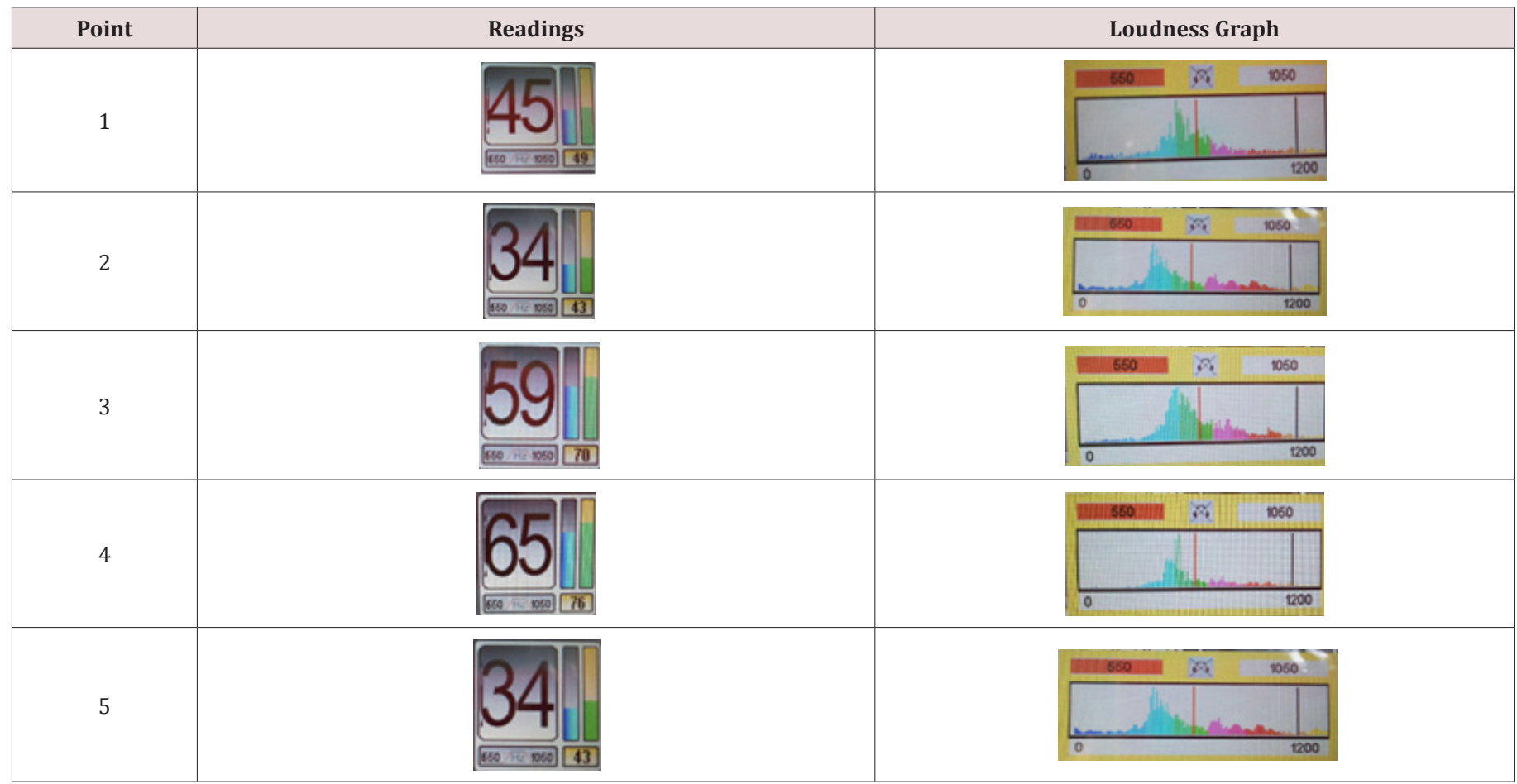

\section{Case Study 2: Wet Surface Detected at the Parking Lot}

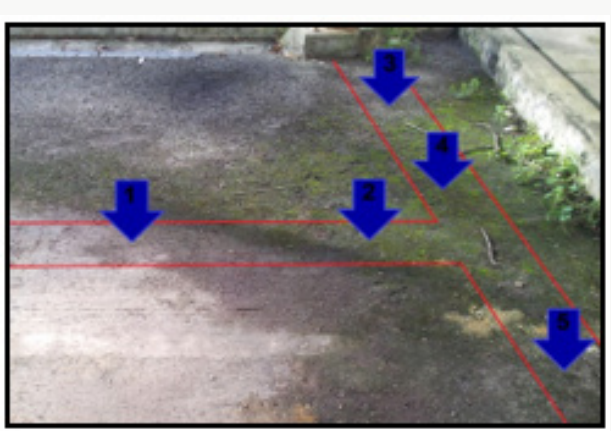

Figure 4: Wet Surface Visible at the Parking Lot Area.

A wet surface had been detected at the parking lot surface near the staffs' residence as shown in Figure 4 The wet surface is obviously detected during peak hours. This is because during peak hours, water consumptions are high. So, a higher-pressure force flows in the underground pipeline thus forces the water escape through the crevice. The water then is pushed up to the surface through soils and resulting in wet surface appears on the ground. The readings are taken from five pinpoints indicated by blue arrows. The red line shows the underground water pipeline path. The acoustic device has been used to determine the pinpoint of the leakage. The readings taken are plotted in Table 2. The results demonstrate that the leakage is highly possible to occur at point 4 as it shows the highest frequency reading. This is the result of vibration from water escaping from the crack or leakage on the pipe. Uniform reading should be accomplished if the pipeline is in good condition. Point 2 also shows a high frequency reading though not as high as point 4 . It can be concluded that the frequency increases as the detector comes close to the source of leakage. The readings at point 1,3 , and 5 are lower compared to point 2 and 4 as they are further from the leakage pinpoint. 
Table 2: Frequency Readings from the Leakage at the Parking Lot.

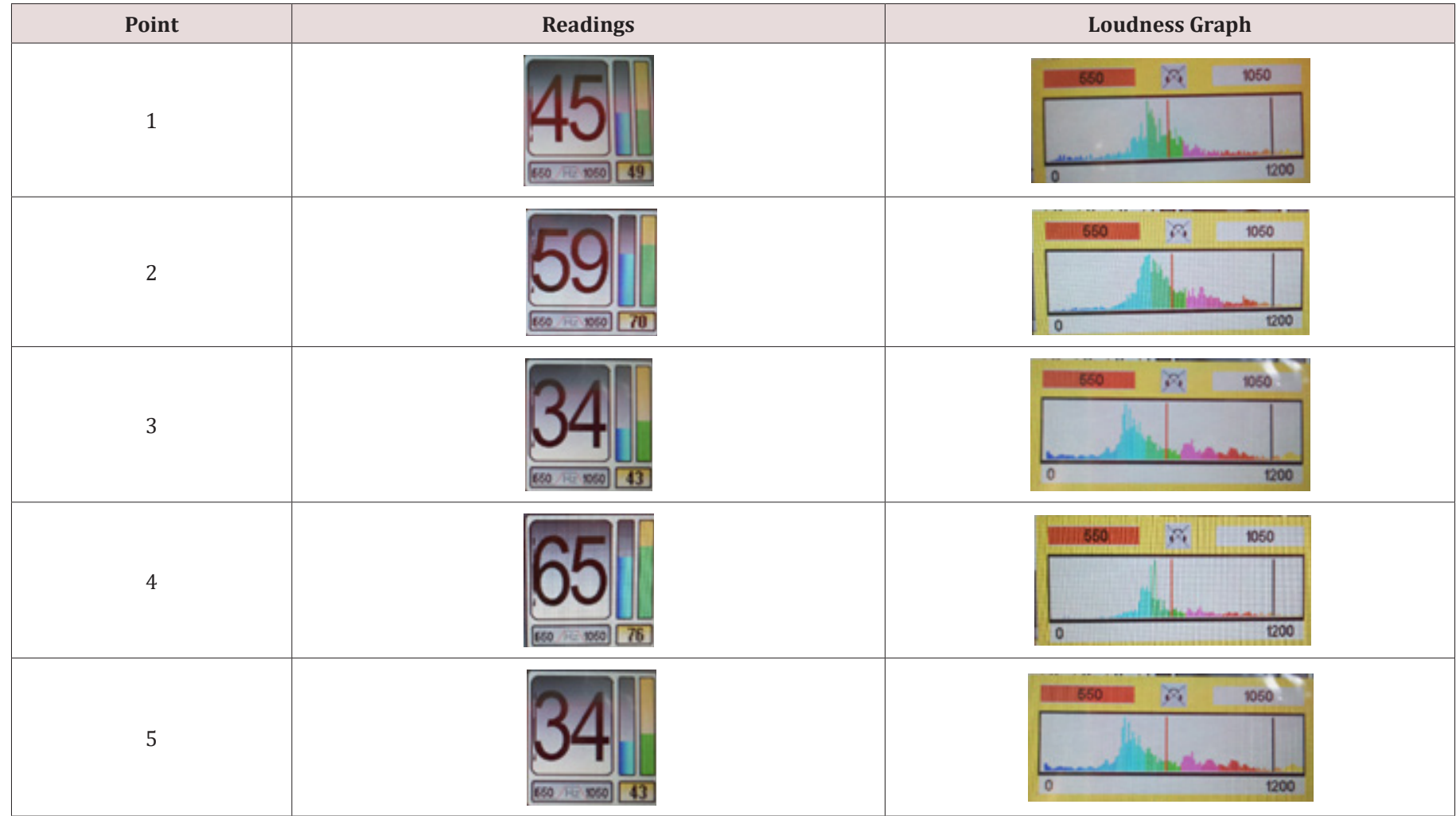

\section{Case Study 3: The Chancellor Building}

Table 3: Frequency Readings of Leakage from Chancellor Building.

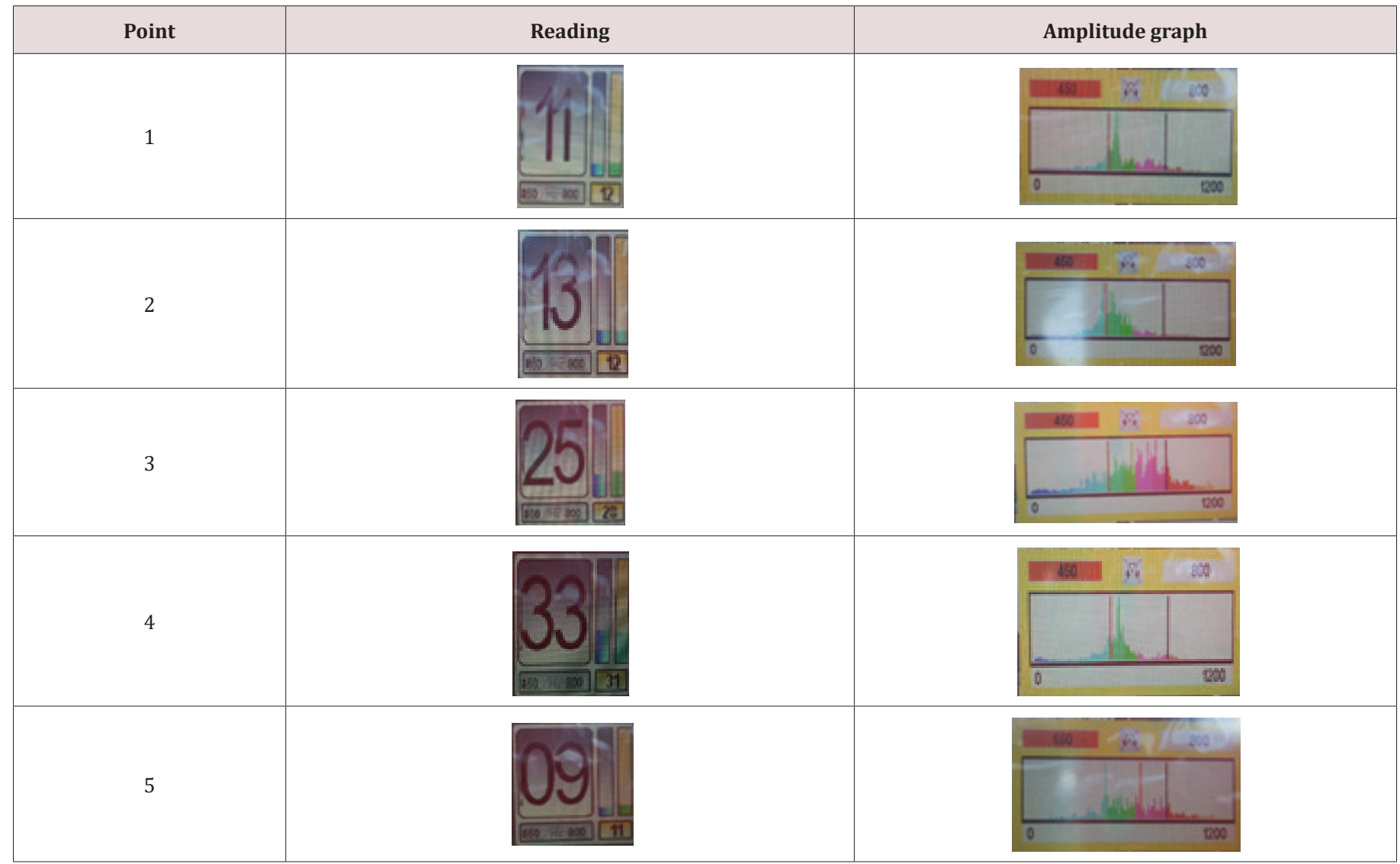




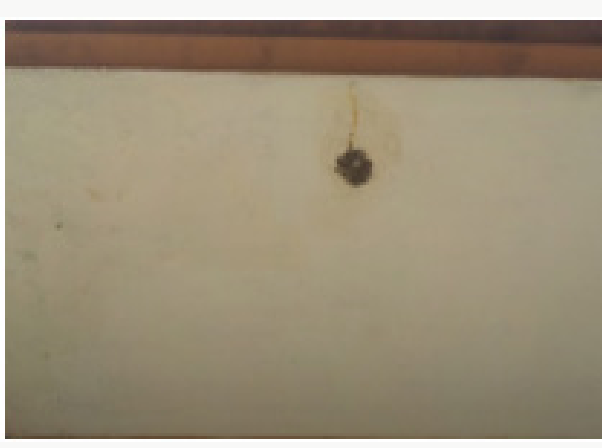

Figure 5: Watermark on the ceiling of Chancellor Building.

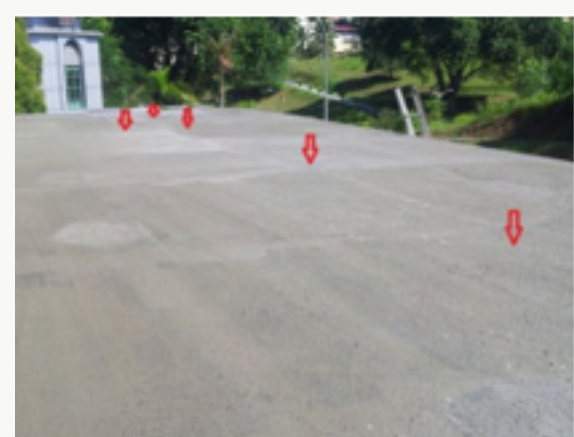

Figure 6: Points of Reading.

Watermark is detected at the ceiling of Chancellor Building as shown in Figure 5 below. Therefore, five frequency readings have been taken from five different places near the watermark as shown in Figure 6. Based on the results displayed in Table 3, there are two possible points of leakage which are at point 3 and 4 . This is because at point 3 and 4 , the device detected highest amplitude of loudness which came from the leakage.

\section{Case Study 4: Leakage at Block C4}

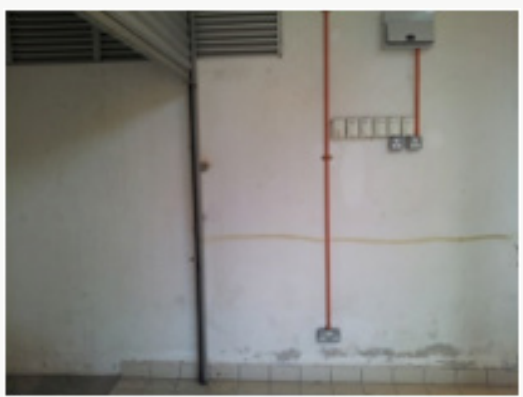

Figure 7: Watermark at Block C4

Watermark has been spotted at Block C4 as shown in Figure 7 Points of interest are labelled as shown in Figure 8 to determine the source of leakage. The results are displayed in Table 4. Based on the results, the highest frequency reading is obtained at point $\mathrm{C}$ followed by point B, A, and D. This is because water leakage occurred at that point causing the pipeline emitted a higher vibration that can be detected by the detector.

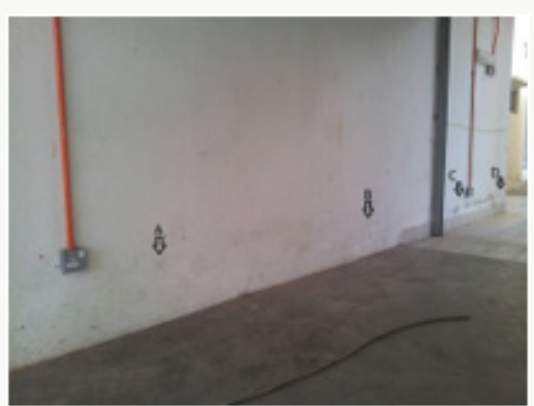

Figure 8: Points of Reading.

Table 4: Frequency Readings of Leakage from Block C4.

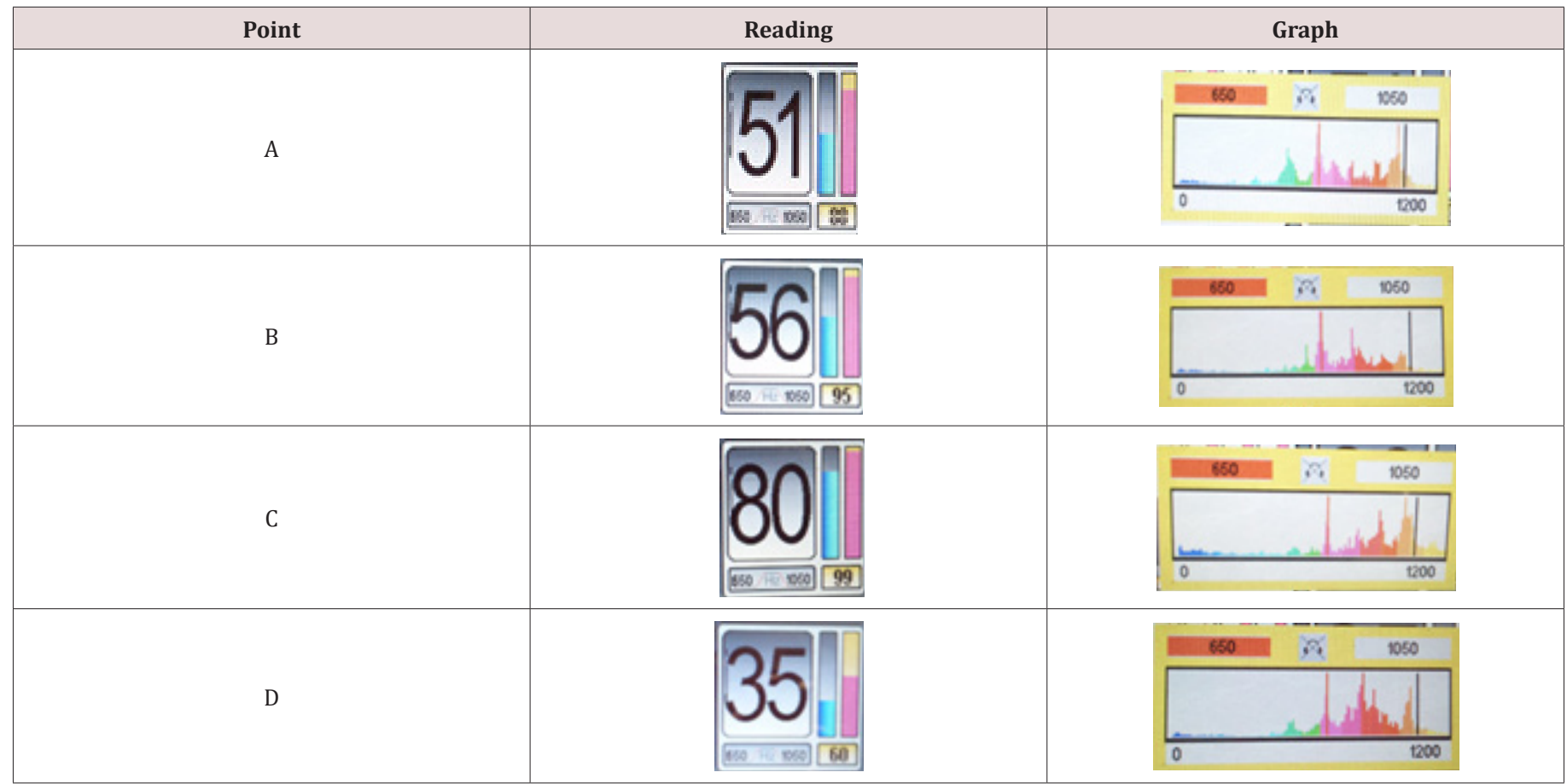




\section{Crack Propagation Theory}

From the results obtained, we can analyse the factor that leads to cracks and leakage. Leakage can occur as the results of high pressure and type of material chosen for pipe. High pressure can cause stress that leads to propagate cracks. Thus, crack propagation theory is studied to determine the suitability on pipe selection. Due to uniformity of loading, an element of the pipe is subjected to normal stress or hoop stress $(\sigma 1)$ and meridian stresses $(\sigma 2)$ in the longitudinal direction. Stresses subjected to pipe wall determined by internal pressure, radius and thickness of the wall and are experienced by every part of the wall pipe.

In order to find maximum stress acting on the pipe wall, hoop stress and meridian stress both need to be calculated. The hoop stress is the stress that occurs at y-plane direction. Meanwhile meridian stress is the force acting on $\mathrm{x}$-plane direction. The pipe sample is shown in Table 5 below.

Table 5: Sample Pipe Parameters.

\begin{tabular}{|c|c|}
\hline Parameters & Value \\
\hline Pressure $(\rho)$ & $28 \mathrm{MPa}$ \\
\hline Radius $(\mathrm{r})$ & $0.08 \mathrm{~m}$ \\
\hline Thickness $(\mathrm{t})$ & $0.006 \mathrm{~m}$ \\
\hline
\end{tabular}

Calculation of hoop stress: -

$$
\sigma \mathrm{h}=\mathrm{pr} / \mathrm{t}
$$

$\sigma \mathrm{h}=(28)(0.08) / 0.006$

$\sigma \mathrm{h}=373.3 \mathrm{MPa}$

Calculation of meridian stress: -

$\sigma \mathrm{m}=\mathrm{pr} / 2 \mathrm{t}$

$$
\begin{gathered}
\sigma \mathrm{m}=(28)(0.08) / 2(0.006) \\
\sigma \mathrm{m}=186.67 \mathrm{MPa}
\end{gathered}
$$

From the calculations, the value of hoop stress is chosen as operating stress. It is chosen because the value of the stress is the maximum stress experienced by the pipe wall. Fracture toughness, $\mathrm{K}_{\mathrm{ic}^{\prime}}$ is the resistance of a material from fracture starting from pre-existing cracks. From this equation we can predict the stress state that is closed to the crack tip accurately. Geometric factor is dimensionless and determined by geometry, loading configuration (load acting on pipe), and the ration of crack length to specimen width.

The equation is given as

$$
\mathrm{K}=\mathrm{Y} \sigma \sqrt{\pi \mathrm{a}}
$$

Where;

$$
\begin{aligned}
& \mathrm{K}=\text { stress intensity factor } \\
& Y=\text { geometric factor } \\
& \sigma=\text { operating stress }=\sigma \max \\
& a=\text { crack length }
\end{aligned}
$$

The stress intensity factor, $\mathrm{K}$ is then compared to plane strain fracture, $\mathrm{K}_{\mathrm{ic}}$ as stated in the Table 4.4. The $\mathrm{K}_{\mathrm{ic}}$ is temperature, strain rate, and microstructure of materials dependant. The magnitude of $\mathrm{K}_{\mathrm{ic}}$ diminishes with increasing strain rate and decreasing temperature. The value of $K_{i c}$ normally increases it with reduction in grain size as composition and other micro structural variables are maintained constant [5].

$\mathrm{Y}=$ in this shape of crack for pipe, 1.12 is taken for the value of geometry factor

$$
\begin{gathered}
\mathrm{a}=(\text { crack length }) / 2 \\
=0.01 / 2=0.005 \mathrm{~m} \\
\mathrm{~K}=\mathrm{Y} \sigma \sqrt{\pi \mathrm{a}} \\
\mathrm{K}=1.12(373.3) \sqrt{ }(\pi(0.005)) \\
\mathrm{K}=52.40 \mathrm{MPa} \sqrt{\mathrm{m}}
\end{gathered}
$$

From calculation made, stress intensity factors the value, $\mathrm{K}$ is greater than plane strain fracture toughness, $\mathrm{K}_{\mathrm{ic}}$ as shown in Table 6 This means the crack on the pipe is propagating.

Table 6: Plane Strain Fracture Toughness [5].

\begin{tabular}{|c|c|}
\hline Material & KIC MPa(m)1/2 \\
\hline \multicolumn{2}{|c|}{ Metals } \\
\hline Aluminium alloy & 36 \\
\hline Steel alloy & 50 \\
\hline Titanium alloy & $44-66$ \\
\hline Aluminium oxide & $14-28$ \\
\hline \multicolumn{2}{|c|}{ Ceramic } \\
\hline Aluminium oxide & $3-5.3$ \\
\hline Soda-lime-glass & $0.7-0.8$ \\
\hline Concrete & $0.2-1.4$ \\
\hline \multicolumn{2}{|c|}{ Polymers } \\
\hline Polymethyl methacrylate & 1 \\
\hline Polystene & $0.8-1.1$ \\
\hline Crack length & $0.01 \mathrm{~m}$ \\
\hline
\end{tabular}

\section{Conclusion}

Cracks and leakage detection in buried water pipeline system at UPNM area was conducted using an acoustic device which is AQUA M 300D. It is found that the pinpoint of cracks and leakage is successfully determined without affecting the pipeline. This study is practical to be used as to detect abnormalities in the underground water pipeline. A theoretical analysis for stress intensity factor also has been investigated. The pipe is modelled as a thin wall cylindrical to calculate the stress acting on the pipe wall. From the data analysed, it can be concluded that the stress intensity factor, $\mathrm{K}$ should not be greater than plane fracture toughness, $\mathrm{K}_{\mathrm{ic}}$ of the pipe material. If the value exceeds, the crack will propagate and lead to leakage. The theoretical calculation gives agreeable result with this study as the $\mathrm{K}$ value exceeds the $\mathrm{K}_{\mathrm{ic}}$, thus resulting in leakage on the pipeline. 


\section{References}

1. Burn S, De Silva D, Eiswirth M, Hunaidi O, Speers A (1999) Pipe Leakage Future Challenges and Solution, Pipes Wagga Wagga Australia.

2. Blazenic M, Samardzic I, Kolunbic Z (2005) Leak detection in Underground Pipelines of Municipal Water Distribution. Advanced Technologies for Developing Countries pp: 481-486.
3. P Runow (1985) The Use of Acoustic Emission Method as Aids to the Structural Integrity Assessment of Nuclear Power Plant. International Journal of Pressure Vessels and Piping 21(3): 157-207.

4. Hunaidi O, Chu W, Wang A, Guan W (2000) Detecting leaks in plastic pipes. American Water Works Association 92(2): 82-94.

5. Callister WD (1994) Materials Science and Engineering: An Introduction. New York: John Wiley \& Sons, USA.

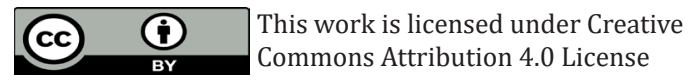

To Submit Your Article Click Here: Submit Article

DOI: 10.32474/OAJESS.2018.01.000108

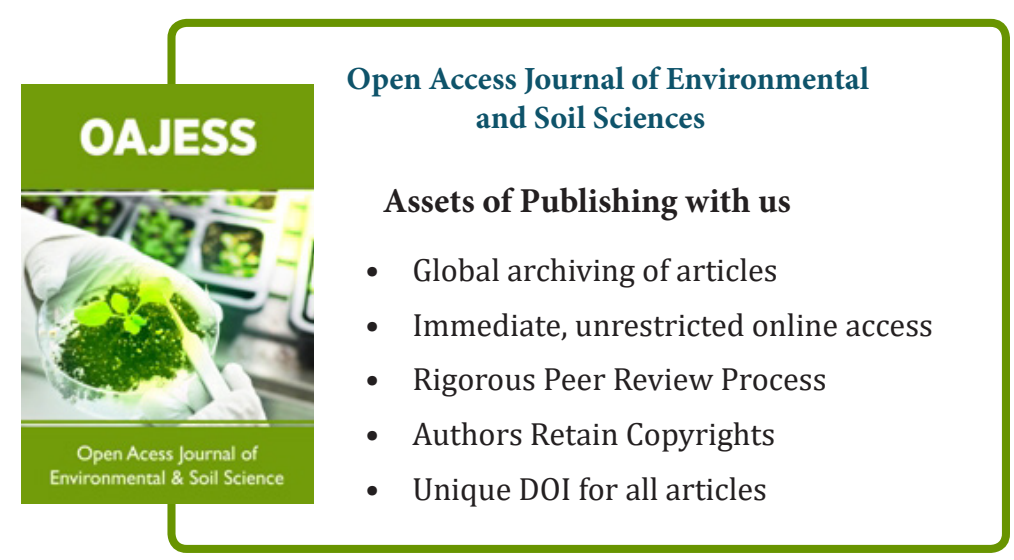

